\title{
Associations between changes in the pattern of suicide methods and rates in Korea, the US, and Finland
}

\author{
Subin Park', Myung Hee Ahn'², Ahrong Lee ${ }^{2}$ and Jin Pyo Hong ${ }^{2^{*}}$
}

\begin{abstract}
Background: The lethality of the suicide method employed is a strong risk factor for the completion of suicide. We examined whether annual changes in the pattern of suicide methods is related to annual changes in suicide rates in South Korea, the United States (US), and Finland.

Methods: We analyzed annual data from 2000-2011 for South Korea and Finland, and 2000-2010 for the US in order to examine trends in the rates and methods of suicide. Data on suicide methods were obtained from the World Health Organization (WHO) mortality database.

Results: Along with an annual rapid increase in suicide rates, the incidence of hanging increased steadily while suicide by self-poisoning steadily decreased in South Korea. In the US, along with an annual increase in suicide rates, the proportion of suicides committed by hanging increased while those committed with the use of firearms steadily decreased. In Finland, annual changes in the suicide rate and suicide method were not statistically significant during the study period.

Conclusions: Our present findings suggest that the increased use of specific lethal methods for suicide, namely hanging, is reflected in the increased suicide rates in the Korean and the US populations. The most effective approach for reducing overall suicide rates may be the implementation of population-based initiatives that reduce both the accessibility (e.g., access to firearms) and the social acceptability (e.g., effective and responsible regulations for reporting suicide) of lethal methods of suicide.
\end{abstract}

Keywords: Suicide, Method, Hanging

\section{Background}

In 2012, South Korea had the highest suicide rate of all countries in the Organization for Economic Cooperation and Development (OECD) [1]. In recent years, suicide rates have increased rapidly and steadily in South Korea: in 1990 an average of 9.8 suicides per 100,000 individuals were observed, and in 2012 the rate was 33.5 suicides per 100,000 individuals.

The lethality of the chosen suicide method is a strong risk factor for suicide completion [2]. Use of firearms and hanging are two of the most lethal suicide with over $80 \%$ case fatality while self-poisoning and self-injurious

\footnotetext{
*Correspondence: jphong@amc.seoul.kr

${ }^{2}$ Department of Psychiatry, Asan Medical Center, Ulsan University College of Medicine, 388-1 Pungnap-2dong, Songpa-gu, Seoul 138-736, South Korea
} Full list of author information is available at the end of the article behavior with sharp objects having lower fatality (less than 5\%) [2,3]. National studies on suicide indicate that the preferred suicide method varies between countries. Some patterns are well known, such as the high proportion of firearm suicides in the United States [4] and the prevalent pesticide suicide in Asian countries in the 1990s [5]. Hanging was the most prevalent suicide methods in many countries including European countries [6], Australia [7], and Canada [8]. In South Korea, use of firearms is very rare, because of strict government restrictions limiting firearms [9]. Hence, a trend toward increased use of hanging among Koreans may partially explain the increased suicide rates.

In our present study, we examined whether annual changes in the pattern of suicide methods is related to the annual change in suicide rates in South Korea. We 
used suicide victims in the United States and Finland as the comparison group for an investigation of trends in suicide rates and methods in South Korea. The United States, where guns are more available, is selected to examine the effect of use of firearms, one of the most lethal method, on suicide rates. Finland is selected because it is the first country to establish a research-based comprehensive national program for suicide prevention, which significantly decreased national suicide rates and earned praises from around the world [10]. In the United States, the suicide rate has increased steadily since 2000 (10.4 suicides per 100,000 individuals), with 12.6 suicides per 100,000 individuals in 2010 . However, the extent of change in suicide rates was not as rapid in the United States compared with South Korea. In Finland, the suicide rate has decreased since 1990, with 30.3 suicides per 100,000 individuals in 1990, 22.5 suicides per 100,000 individuals in 2000, and 16.9 suicides per 100,000 individuals in 2011 [11]. We hypothesize that the increased use of more lethal methods such as hanging and firearms may be associated with the increase in the total suicide rates, and that this association may be more prominent in countries where the use of less lethal method is replaced by more lethal method, than in countries where the use of one specific lethal method of suicide is replaced by other specific lethal method.

\section{Methods}

We analyzed annual data during the period 2000-2011 to examine trends in suicide rates and suicide methods in three countries. Data on suicide rates and methods among people aged 10 years over were obtained from the World Health Organization (WHO) mortality database [11]. The most recent data were from 2011 for South Korea and Finland, and from 2010 for the United States. Suicide methods were classified into five categories according to the ICD-10 codes: self-poisoning (X60X69), hanging (X70), firearms (X72-74), jumping from a high place (X80), and others (X71, X75-X79, X81-X84).

The WHO obtains data on deaths that includes age, sex, and cause of death, as reported annually by member states through civil registration systems (e.g., the Korean National Statistical Office, the National Center for Health Statistics of the United States, and the Statistics Finland), and compiles the data in the WHO mortality database. Based on country-reported data and the use of additional data sources such as population censuses and household surveys, the WHO and its partners regularly estimate key mortality statistics to improve data comparability across countries and years. In addition, the WHO estimates the completeness and coverage of reported data, and assesses the quality of cause-of-death data. According to the WHO, the rate of civil registration coverage of cause of death was $100 \%$ in all three countries. The rate of ill-defined causes in cause-of-death registration was $15.4 \%$ in South Korea, $6.7 \%$ in the United States, and 2.4\% in Finland in 2010.

We performed Spearman correlation analyses to assess trends in suicide rates over the 12-year period and potential correlations between specific suicide methods and suicide rates. All statistical analyses were performed using SPSS (version 21.0; SPSS Inc., Chicago, IL), with statistical significance defined as an alpha level of 0.05 / ( 5 types of suicide methods $\times 3$ countries $)=0.0033$.

\section{Results}

Annual suicide rates in South Korea and Finland between 2000 and 2011 as well as annual suicide rates in the United States between 2000 and 2010, are shown in Figure 1. During this period, suicide rates for males in South Korea rapidly increased from 18.8 to 43.3 suicides per 100,000 individuals, and from 8.3 to 20.1 suicides per 100,000 individuals for females. On the other hand, suicide rates among the Finnish population decreased from 34.56 to 26.76 suicides per 100,000 individuals for males and 10.94 to 7.29 suicides per 100,000 individuals for females. The United States suicide rate slightly but steadily increased from 17.1 to 20.2 suicides per 100,000 individuals for males and from 4.0 to 5.2 suicides per 100,000 individuals for females.

In South Korea, self-poisoning was the most common method of suicide for both males and females until the early 2000's. The rate of self-poisoning significantly and steadily decreased since $2001(\mathrm{r}=-0.96, P<0.001$ for both males and females). In contrast, the rate of hanging significantly increased $(\mathrm{r}=-0.96, P<0.001$ for males and $\mathrm{r}=0.93$, $P<0.001$ for females), and hanging has been the most common method of suicide among Korean males since 2003 and among Korean females since 2005 (Figure 2). For both Korean males and females, there was a significant positive correlation between suicide rate and the rate of hanging $(r=0.90, P<0.001$ and $r=0.95, P<0.001$, respectively), and a negative correlation between suicide rate and both the rate of poisoning $(\mathrm{r}=-0.88, P<0.001$ and $\mathrm{r}=-0.98, P<0.001$, respectively) and the rate of other methods $(\mathrm{r}=-0.92, P<0.001$ and $\mathrm{r}=-0.95, P<0.001$, respectively).

During the study period, firearms were the most common method of suicide in American males; however, the rate of suicide by firearms decreased significantly $(\mathrm{r}=-0.92, P=0.001)$, and the rate of hanging increased significantly $(r=0.97, P<0.001)$ in the United States. Between 2001 and 2010, poisoning was the most common suicide method among American females. During the same period in the United States, firearms were the second most common suicide method among American females, but the rate decreased significantly 

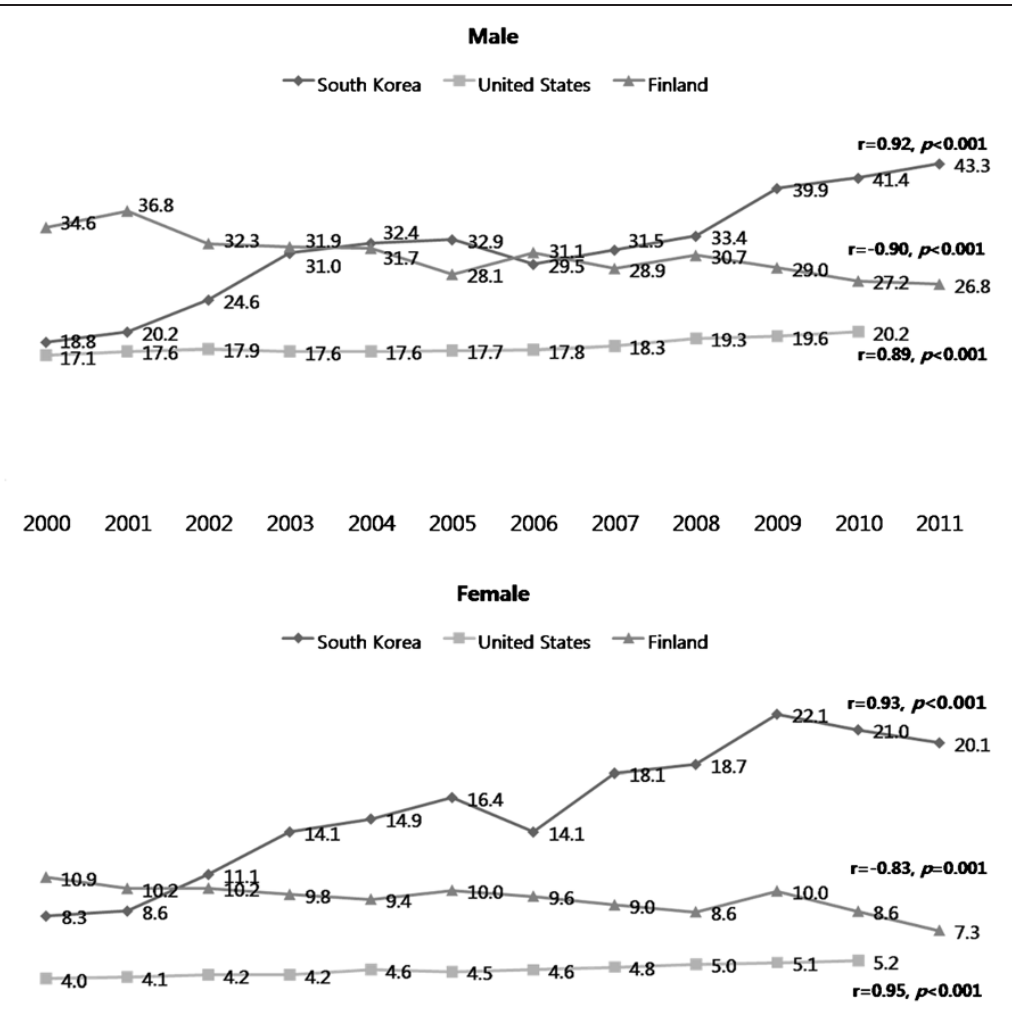

$\begin{array}{llllllllllll}2000 & 2001 & 2002 & 2003 & 2004 & 2005 & 2006 & 2007 & 2008 & 2009 & 2010 & 2011\end{array}$

Figure 1 Annual trends in suicide rates in South Korea, the United States, and Finland.

( $\mathrm{r}=-0.86, P=0.001)$. In contrast, the rate of hanging increased significantly and steadily $(r=0.96, P<0.001)$, but the rate of jumping decreased significantly $(r=-0.90$, $P<0.001$ ) among American females (Figure 3).

Among both American males and females, there was a significant positive correlation between the suicide rate and the rate of hanging $(r=0.83, P=0.002$ and $r=0.96$, $P<0.001$, respectively), and a negative correlation between the suicide rate and the rate of suicide by firearms $(\mathrm{r}=-0.80, P=0.003$ and $\mathrm{r}=-0.84, P=0.001$, respectively). In addition, there was a significant negative correlation between the suicide rate and the rate of suicide by jumping in American females $(r=-0.89, P<0.001)$.

In Finland, the most common method of suicide in males was hanging, while self-poisoning was the most common method of suicide in Finnish females during the study period. The trends for the changes in suicide method were not statistically significant for both males and females in Finland, and there was no significant correlation between suicide rate and the rate of any specific suicide methods (Figure 4).

\section{Discussion}

We hypothesized that an increased use of a specific lethal suicide method was related to an increase in overall suicide rates. This hypothesis is supported by the findings of our present study, at least in case of South Korea. The proportion of highly lethal methods, namely hanging, increased, and the proportion of less lethal methods such as self-poisoning decreased among South Korean males and females, which were accompanied by a trend of increased annual suicide rates. This association between the proportion of suicides by hanging and annual changes in overall suicide rates was less prominent in the United States where the use of firearms, which is an even more lethal method, was replaced by hanging. This association was not observed in Finland, where annual changes in the suicide rate and the pattern of suicide methods were not prominent during the study period.

It should be noted that drug poisoning was a suicide method that has been commonly used in the past in South Korea, but has become less available in recent years due to strict regulations [12], and this may explain an increased use of hanging. In 2000, the Pharmacist Law was revised to restrict dispensing of prescription medications and in 2005, the Agrochemicals Control Act was revised to limit pesticide sales and purchases more strictly. These findings suggest that government restrictions limiting pesticide purchases and drug prescriptions are effective strategies for reducing suicide by 

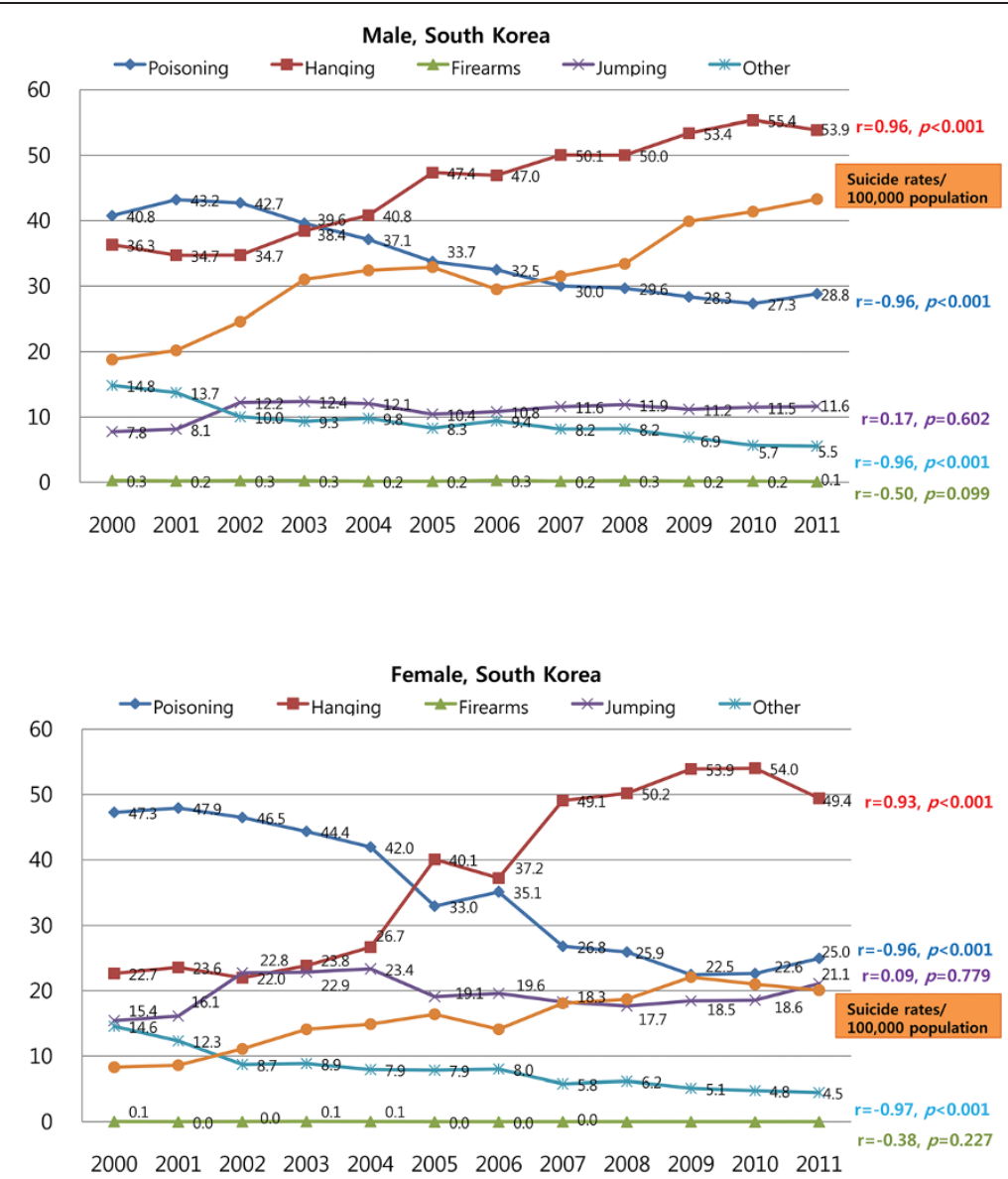

Figure 2 Trends in the suicide methods employed by Korean males and females between 2000 and 2011.

these methods [13]. However, challenges remain for the prevention of suicide by hanging because of the difficulty of regulating and limiting the means to do so [14].

With regard to the rapid increase in suicide by hanging in South Korea since 2005, one consideration is the ability of celebrity suicides to induce copycat suicides, particularly in females [15]. The media's reporting of suicide and its fictional portrayal on television are known to influence suicidal behavior, particularly the choice of method used [16-18]. Media guidelines for the sensational reporting of suicide are needed to reduce the portrayal of fictional suicides by lethal methods [19]. Suicide by hanging might be influenced by altered public perception of its acceptability [20]. Previous qualitative study of 22 suicide attempters that included 8 respondents who had attempted hanging showed that hanging was adopted for two main reasons, the anticipated nature of a death from hanging and accessibility [21]. Suicide attempters favoring hanging considered it as a clean, rapid and painless method with little awareness of dying and an easy method without the need of planning or technical knowledge. In contrary, respondents who rejected hanging recognized that it could be slow, painful, and messy method that needed technical knowledge for implementation. Authors suggested that prevention strategies should focus on countering perceptions of hanging as a clean, rapid, and painless method that is easily implemented [21]. Media could contribute to generate negative social perceptions of hanging [18]. Thus, suicide prevention agencies must work with the media to reduce the socio-cultural acceptability of hanging. In South Korea, which has the highest Internet penetration rate in the world [22], web-based programs to reduce the socio-cultural acceptability of hanging may be also effective. However, even if hanging suicides decreased by decreasing social acceptability of this lethal method, it could be replaced by another lethal method such as jumping and charcoal burning. Therefore, for an overall decrease in suicide rates, there is a need to adopt comprehensive, population-based approaches involving efforts to raise awareness about suicide prevention, reinforcement of social safety nets, promotion of socio-cultural beliefs that discourage suicide, and adequate prevention and treatment of depression and alcohol abuse, proven risk factors for suicide [23]. 

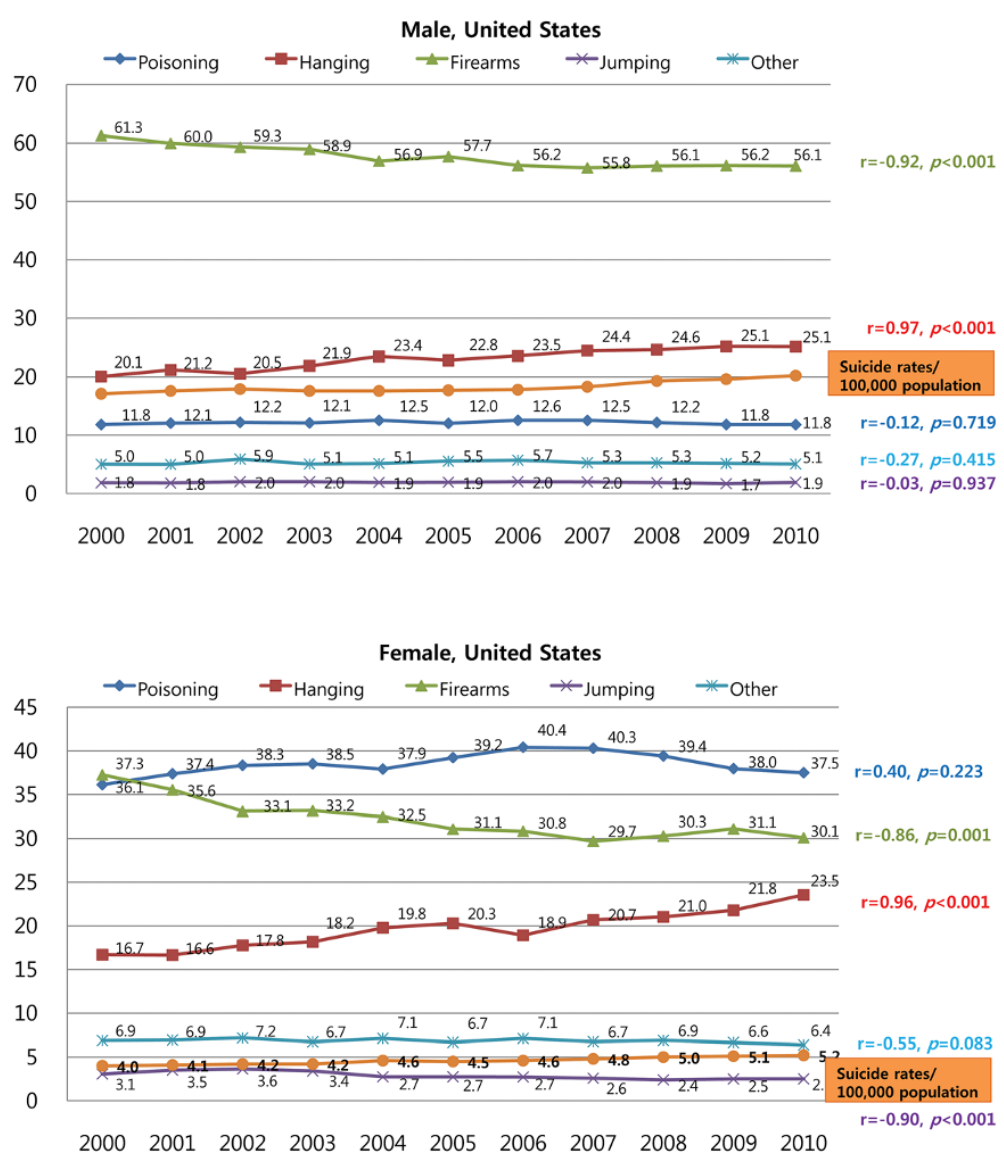

Figure 3 Trends in the suicide methods employed by American males and females between 2000 and 2010.

Firearms were the most common method of suicide among American males and the second most common method among American females. In the United States, several firearm policies have been enacted to limit access to firearms, especially for underage youth. In 1994, a federal law established 18 as the minimum legal age for the possession or purchase of handguns, including sales by gun owners who are not licensed dealers. American states vary in their requirements for gun ownership prohibition laws, such as banning of minors and people with history of felony, domestic violence offence, and mental or substance use problems [24]. Furthermore, gun safe storage laws, often referred to as child access prevention (CAP) laws, were enacted to prevent young people from gaining access to firearms. Most laws require gun owners to keep their guns in locked storage. A previous study demonstrating the effectiveness of CAP laws [25] found that the restriction of access to firearms is at least somewhat effective in decreasing the incidence of suicide by firearms and overall suicide rates in youth. Increased waiting period for the obtainment of handgun reduced suicide by firearm use among American adults over the age of 55 [26]. However, the reduction in suicide by firearms was offset by an increase in suicide by hanging, another lethal method, which resulted in no change in the overall suicide rate in the American population.

In Finland, the most common suicide methods were hanging in males and self-poisoning in females. In 1985, Finland established a research-based comprehensive national program for suicide prevention [10]. The suicide rate continued to increase until 1990, but then decreased by $20 \%$ between 1991 and 1996, and has been declining ever since. A comprehensive national program for suicide prevention in Finland included efforts to raise awareness about suicide prevention (e.g., recognizing the warning sign of suicide), efforts to reduce the social acceptability of suicide (e.g., effective and responsible regulations for reporting suicide), and efforts to limit the accessibility of a specific method of suicide (e.g., limiting access to firearms) [10]. Such comprehensive populationbased approaches may have helped decrease suicide attempts by all means, rather than only decrease suicides attempts by specific methods, leading to an overall decrease in suicide rates. However, because the trends for changes in suicide method were not significant 

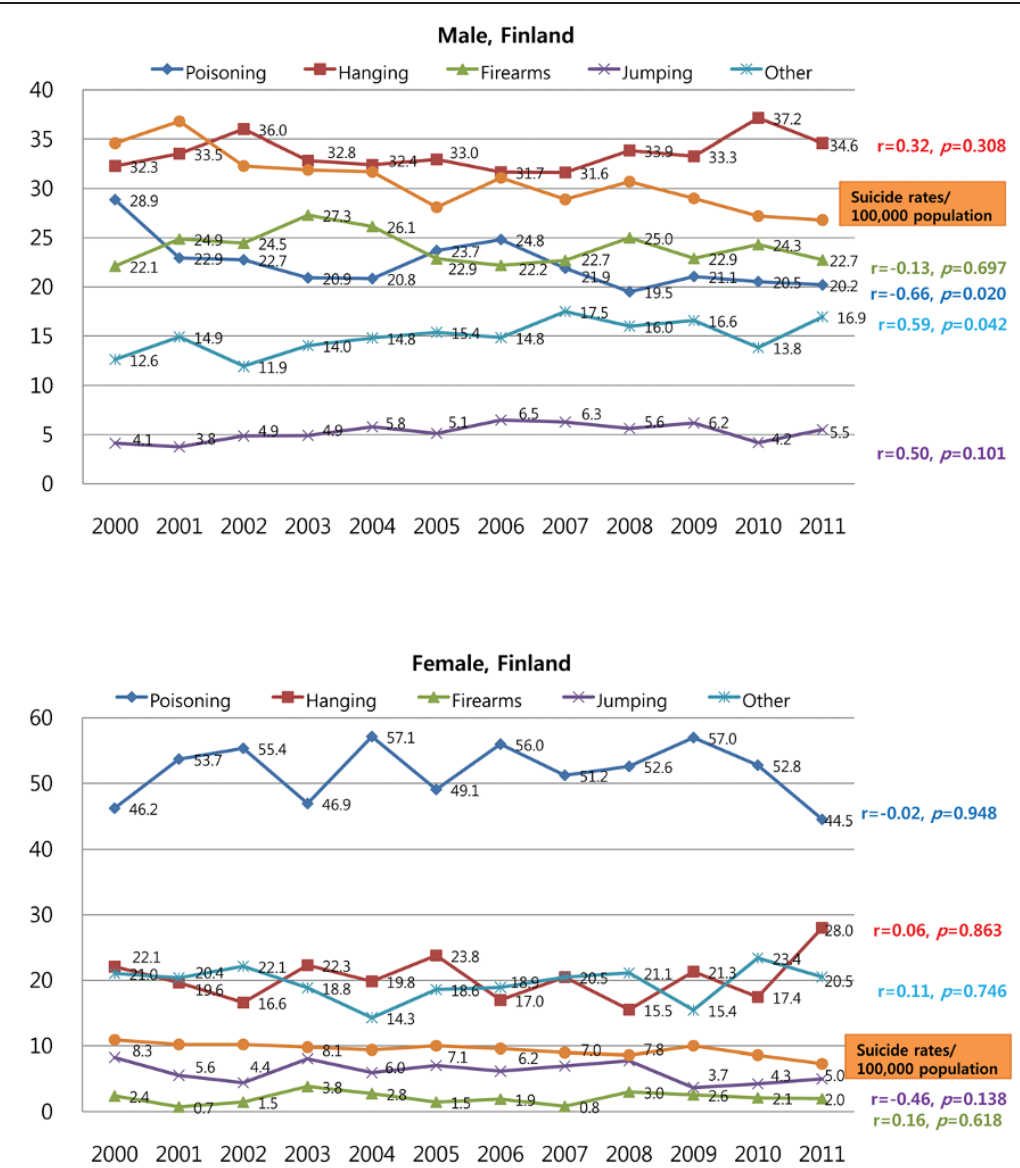

Figure 4 Trends in the suicide methods employed by Finnish males and females between 2000 and 2011.

during the study period, we could not conclude with certainty that the decreased incidence of suicide attempts using lethal methods was related to the decrease in overall suicide rates in this country.

We must interpret the results of this study within the context of the following limitations. First, government case registries may underestimate the number of deaths due to suicide because many suicides may have been classified as "undetermined" deaths [27]. Second, although our focus was on the impact of suicide methods on annual changes in suicide rates, various other factors may have influenced the suicide rates, including social situations such as economic crises and celebrity suicides, which were not considered. Finally, subgroup analysis according to the ethnicity/race was not available for the heterogeneous United States population.

\section{Conclusions}

Our present findings suggest that the increased use of hanging as a suicide method in South Korea is related to an increase in the overall suicide rate. Limiting access to lethal methods of suicide (e.g., firearms) is an effective strategy for reducing suicide by that particular method, but replacement by another lethal method (e.g., hanging) may lead to no overall decrease in the suicide rate. In addition, limiting access to relatively less lethal methods of suicide (e.g., drugs) can be easily replaced by more readily available and lethal methods of suicide (e.g., hanging). Therefore, the most fruitful approach to reducing overall suicide rates may be through population-based initiatives that reduce both the accessibility and the social acceptability of lethal methods of suicide.

\section{Competing interests}

None of the authors have any financial interest in the study, or any other conflict of interest.

\section{Authors' contributions}

JPH designed the study, supervised the data collection, and assisted with writing the article. SP wrote the paper and carried out the statistical analysis. $\mathrm{AL}$ and MHA acquired the data and assisted with writing the article. All authors read and approved the final manuscript.

\section{Acknowledgements}

This work was supported by the Korea Healthcare Technology R\&D project, Ministry of Health \& Welfare, Republic of Korea (grant number A120051) and by the Basic Science Program through the National Research Foundation of Korea (NRF) Grant funded by the Korean Government(MSIP) (No. 2013R1A1A3008158). 


\section{Author details}

'Department of Psychiatry, Seoul National Hospital, 398 Neungdong-ro, Gwangin-gu, Seoul, South Korea. ${ }^{2}$ Department of Psychiatry, Asan Medical Center, Ulsan University College of Medicine, 388-1 Pungnap-2dong, Songpa-gu Seoul 138-736, South Korea.

Received: 18 April 2014 Accepted: 27 May 2014

Published: 4 June 2014

\section{References}

1. OECD: OECD Health Data 2012; 2012. Available at: www.who.int/healthinfo/ statistics/mortality/en/index1.html. [Accessed on 16 April 2014].

2. Spicer RS, Miller TR: Suicide acts in 8 states: incidence and case fatality rates by demographics and method. Am J Public Health 2000, 90 (12):1885-1891.

3. Shenassa ED, Catlin SN, Buka SL: Lethality of firearms relative to other suicide methods: a population based study. J Epidemiol Community Health 2003, 57(2):120-124

4. Brent DA: Firearms and suicide. Ann N Y Acad Sci 2001, 932:225-239. discussion; 239-240.

5. Eddleston M: Patterns and problems of deliberate self-poisoning in the developing world. QJM 2000, 93(11):715-731.

6. Varnik A, Kolves K, van der Feltz-Cornelis CM, Marusic A, Oskarsson H, Palme A, Reisch T, Scheerder G, Arensman E, Aromaa E, Giupponi G, Gusmäo R, Maxwell M, Pull C, Szekely A, Sola VP, Hegerl U: Suicide methods in Europe: a gender-specific analysis of countries participating in the "European Alliance Against Depression". J Epidemiol Community Health 2008, 62(6):545-551.

7. Wilkinson D, Gunnell D: Comparison of trends in method-specific suicide rates in Australia and England \& Wales, 1968-97. Aust N Z J Public Health 2000, 24(2):153-157.

8. Langlois S, Morrison P: Suicide deaths and suicide attempts. Health Rep 2002, 13(2):9-22.

9. Im JS, Choi SH, Hong D, Seo HJ, Park S, Hong JP: Proximal risk factors and suicide methods among suicide completers from national suicide mortality data 2004-2006 in Korea. Compr Psychiatry 2011, 52(3):231-237.

10. Kerkhof AJ: The Finnish national suicide prevention program evaluated. Crisis 1999, 20(2):50-63.

11. WHO: WHO Mortality Data and Statistics 2013; Available at: http://www.who. int/healthinfo/statistics/mortality_rawdata/en/index.html. [Accessed on 16 April 2014].

12. Lee WJ, Cha ES, Park ES, Kong KA, Yi JH, Son M: Deaths from pesticide poisoning in South Korea: trends over 10 years. Int Arch Occup Environ Health 2009, 82(3):365-371.

13. Leenaars A, Cantor C, Connolly J, EchoHawk M, Gailiene D, He ZX, Kokorina N, Lester D, Lopatin AA, Rodriguez M, Schlebusch L, Takahashi Y, Vijayakumar L, Wenckstern S: Controlling the environment to prevent suicide: international perspectives. Can J Psychiatry 2000, 45(7):639-644.

14. Ohberg A, Lonnqvist J, Sarna S, Vuori E, Penttila A: Trends and availability of suicide methods in Finland. Proposals for restrictive measures. Br J Psychiatry 1995, 166(1):35-43.

15. Jeong J, Shin SD, Kim H, Hong YC, Hwang SS, Lee EJ: The effects of celebrity suicide on copycat suicide attempt: a multi-center observational study. Soc Psychiatry Psychiatr Epidemiol 2012, 47(6):957-965

16. Hawton K, Williams K: Influences of the media on suicide. BMJ 2002 325(7377):1374-1375.

17. Pirkis J, Blood RW: Suicide and the media. Part I: Reportage in nonfictional media. Crisis 2001, 22(4):146-154.

18. Biddle L, Gunnell D, Owen-Smith A, Potokar J, Longson D, Hawton K, Kapur $\mathrm{N}$, Donovan J: Information sources used by the suicidal to inform choice of method. J Affect Disord 2012, 136(3):702-709.

19. Gunnell D, Bennewith O, Hawton K, Simkin S, Kapur N: The epidemiology and prevention of suicide by hanging: a systematic review. Int J Epidemiol 2005, 34(2):433-442.

20. Cantor $\mathrm{CH}$, Baume PJ: Access to methods of suicide: what impact? Aust N Z J Psychiatry 1998, 32(1):8-14.

21. Biddle L, Donovan J, Owen-Smith A, Potokar J, Longson D, Hawton K, Kapur N, Gunnell D: Factors influencing the decision to use hanging as a method of suicide: qualitative study. Br J Psychiatry 2010, 197(4):320-325.

22. Korea National Statistical Office: National Statistics Report. Seoul: Korea National Statistical Office: 2009
23. World Health Organization: Public Health Action for the Prevention of Suicide. Geneva: World Health Organization; 2012.

24. Rodriguez Andres A, Hempstead K: Gun control and suicide: the impact of state firearm regulations in the United States, 1995-2004. Health Policy 2011, 101(1):95-103.

25. Webster DW, Vernick JS, Zeoli AM, Manganello JA: Association between youth-focused firearm laws and youth suicides. JAMA 2004 292(5):594-601.

26. Ludwig J, Cook PJ: Homicide and suicide rates associated with implementation of the Brady Handgun Violence Prevention Act. JAMA 2000, 284(5):585-591.

27. Marusic A, Roskar S, Zorko M: Undetermined deaths: are they suicides? Croat Med J 2003, 44(5):550-552.

doi:10.1186/1752-4458-8-22

Cite this article as: Park et al.: Associations between changes in the pattern of suicide methods and rates in Korea, the US, and Finland. International Journal of Mental Health Systems 2014 8:22.

\section{Submit your next manuscript to BioMed Central and take full advantage of:}

- Convenient online submission

- Thorough peer review

- No space constraints or color figure charges

- Immediate publication on acceptance

- Inclusion in PubMed, CAS, Scopus and Google Scholar

- Research which is freely available for redistribution

Submit your manuscript at www.biomedcentral.com/submit
C Biomed Central 